\section{Juan Verdaguer Tarradella (1934-2020). Un Maestro de la Medicina}

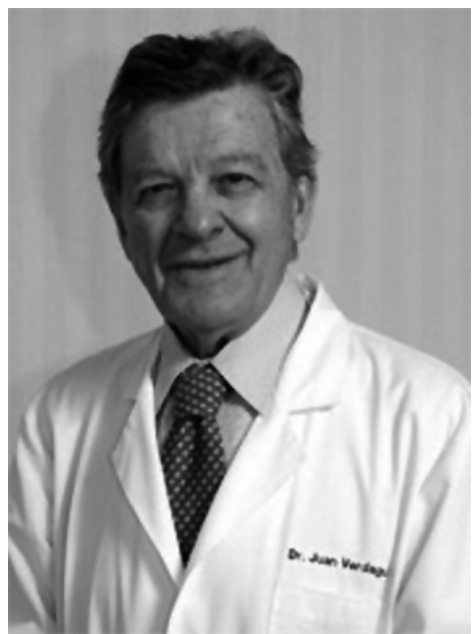

Estando de vacaciones, un llamado telefónico nos comunicó el 25 de febrero que había fallecido Juan Verdaguer Tarradella. No obstante que sabíamos de su grave enfermedad, fue un golpe extremadamente duro para muchos entre los que me incluyo. Juan fue un médico notable, sabio, generoso en compartir su saber, sin usar muchas palabras, pero con una sonrisa permanente se hacía muy próximo a todos. En lo formal, fue profesor de oftalmología, pero en lo real fue mucho más que eso: un modelo de médico y un maestro formador de oftalmólogos. Estudió medicina en la Universidad de Chile egresando en 1957 como el mejor alumno de su promoción. Se especializó en Oftalmología en esa misma Universidad y luego realizó estudios en las Universidades de Harvard y Columbia. En 1964 se diplomó como oftalmólogo en el American Board of Ophthalmology obteniendo una vez más el primer lugar en el examen correspondiente.

Ejerció su profesión por más de sesenta años atendiendo a pacientes y enseñando a estudiantes de pre y postgrado. Lo hizo en la Universidad de Chile y en el último tiempo en la Universidad de Los Andes. Fundó y fue el primer presidente de la Asociación de Profesores Universitarios de Oftalmología de la Asociación Pan Americana de la especialidad estableciendo los requisitos mínimos para los programas de residencia en esa disciplina y creando un registro de los programas acreditados. Presidió la Sociedad Chilena de Oftalmología, fue Miembro de Número de la Academia de Medicina del Instituto de Chile y de la Academia Ophthamologica Internationalis en la cual fue miembro de su comité Ejecutivo y luego su Vicepresidente, presidió la Pan American Association of Ophthalmology, dictó Conferencias de Honor en diferentes países, fue designado Miembro Honorario y Profesor Honorario de muchas sociedades oftalmológicas y universidades extranjeras, ejerció a nivel nacional e internacional muchas otras funciones y obtuvo distinciones que reconocían su sabiduría, su nobleza, su amor por la medicina, su preocupación por lo social.

Su compromiso con la sociedad se evidenció en su trabajo diario con los pacientes, pero se hizo especialmente manifiesto cuando en 1989 organizó y coordinó la "Primera Zona Libre de Catarata en Chile en San Vicente de Tagua Tagua", que consistió en la movilización de muchos oftalmólogos para detectar y tratar esta causa de ceguera, acercando la medicina a personas que no podían acceder a ella. Fue el comienzo de múltiples giras de profesionales semejantes en el futuro.

Dedicó mucho esfuerzo a combatir la Retinopatía Diabética, principal causa de ceguera irreversible en Chile. Promovió y coordinó su búsqueda en pacientes de consultorios y en el año 1999 organizó el día $\mathrm{D}$ que consistió en la pesquisa de la afección en 16 países de América y centenares de ciudades en un solo día. Fue miembro de organizaciones internacionales que han confeccionado guías clínicas para el mejor manejo de esta enfermedad. En los últimos años se dedicó a desarrollar en conjunto con la Facultad de Ingeniería de la Universidad de Chile, un programa de detección automática de esta afección con cámara fotográfica digital.

El año 2013 obtuvo el Premio Nacional De Medicina de Chile que imparten el Colegio Médico de Chile, la Asociación de Sociedades Médicas, la Asociación de Facultades de Medicina y la Academia Chilena de Medicina reconociendo "la obra de aquellos médicos que han sobresalido entre sus pares en el área de la clínica o de la salud pública y que, además, haya tenido un rol destacado en docencia, administración académica o investigación". Lo postularon sus pares fundamentando que era "el oftalmólogo más influyente que ha visto la oftalmología nacional en los últimos 50 
años y uno de los más importantes a través de toda su historia".

Pero la medicina y la oftalmología no eran todo para él. Tenía una cultura vasta y dictaba conferencia acompañadas de diapositivas en las que relataba la vida y obra de grandes artistas como Van Gogh, Caravaggio, Goya y Klimt. También se dio tiempo para seguir con un grupo de colegas un ciclo sobre ópera que dictaba un crítico musical. Juan Verdaguer, por su espíritu humanista y de servicio público, su sabiduría, su relación con los demás, su extensa labor educacional y su prestigio nacional e internacional, permanecerá por siempre en el pedestal más alto de los médicos chilenos de todos los tiempos. En la Academia Chilena de Medicina seguiremos sintiendo su presencia por muchos años.

Rodolfo Armas Merino ${ }^{1}$ ${ }^{1}$ Presidente Academia Chilena de Medicina 